\title{
ANALISIS PEMBELAJARAN PKLH SECARA TERINTEGRASI DENGAN PELAJARAN LAIN DI SMP
}

\author{
Mithen Lullulangi \\ PKLH PPS Universitas Negeri Makassar, Sulawesi Selatan, Indonesia \\ mithen@unm.ac.id
}

(C) 2018 - UEJ Program Studi Pendidikan Kependudukan dan Lingkungan Hidup

Universitas Negeri Makassar. Ini adalah artikel dengan akses terbuka dibawah Licensi CC BY-NC-4.0 (http:/creativecommons.org/licenses/by-nc/4.0)

\begin{abstract}
.
This study aims to determine the success of the program of Population and Environmental Education (PKLH) especially to evaluate the three main shutter in PKLH, ie cognitive shutter, affective shutter, and psychomotor shutter taught in an integrated manner with other subjects in Sekolah Menengah Pertama (SMP), Negeri 1 Balla Kecamatan Balla Mamasa Regency. The population of this study is all students of SMP Negeri 1 Balla, which consists of Class VII $=97$ people, Class VIII $=88$ people, so the population $=185$ people. The sample in this study was determined by 134 students, taken by probability proportionate stratified random sampling. The research variables are: 1) The domain of thinking process (cognitive domain), 2) Affective domain and 3) the psychomotor domain of PKLH material. The data in this research is the result of the test to the respondent, that is the test done to know the knowledge, attitude, and skill of the students about things related to PKLH material. Data were analyzed descriptively and multiple regression using SPSS software as a tool. The results showed that: 1) The domain of the thinking process (cognitive domain), is in the low category, 2) Affective domain is in the medium category, and 3) The psychomotor domain is in the medium category. In addition, the result of multiple regression analysis shows that there is a significant relationship between the variables of thinking process and the sphere of attitude toward the skill domain, with an influence value of $68.4 \%$ about PKLH material.
\end{abstract}

Keywords: Cognitive domain, affective domain, and psychomotor domain, Population and Environment Education.

\section{PENDAHULUAN}

Pendidikan sangat dinamis dan telah mengalami revolusi di dalam konsep dan ideologinya. Hal ini disebabkan oleh perkembangan kehidupan yang juga mengalami perubahan yang mendasar. Untuk mengakomodir kebutuhan tersebut harus dilakukan penyetelan ulang terhadap konsep pendidikan. Hal ini dikemukanan mantan Menteri Pendidikan Nasional Bambang Sudibyo pada saat membuka pertemuan Forum Kebijakan Selatan-Selatan, di Hotel Atlet Century Park, Jakarta, Senin (21/04/2008). Lebih lanjut, dikatakan bahwa pendidikan untuk pembangunan berkelanjutan atau education for sustainable development (ESD) merupakan sebuah konsep pendidikan yang tidak hanya bervisi kepada pendidikan murni, tetapi sekaligus menggabungkan konsep pembangunan dari perspektif ekonomi, sosial, budaya, dan lingkungan.

Selanjutnya, Kemendiknas mengemukakan akan memasukkan konsep pembangunan berkelanjutan (sustainable development) ke dalam lembaga pendidikan, baik formal, informal, maupun nonformal mulai tahun 2011. Pendidikan tentang pembangunan berkelanjutan (education for sustainable development/ESD) di Indonesia sudah mulai dilaksanakan melalui program sekolah sehat dan sekolah hijau, dimana model pendidikan seperti ini menurut Mendiknas telah menjadi rujukan bagi negara lain, terutama di kawasan Asia Pasifik. "Konsep ESD harus dituangkan sejak dari PAUD (Pendidikan Anak Usia Dini). Semua lini harus dikenalkan tentang pendidikan lingkungan," kata mantan Mendiknas, Mohammad Nuh, saat membuka kegiatan Asia- Pacific Regional Center of Expertise (RCE) Conference di Sekolah Pascasarjana UGM, Rabu (12/1-2011). 
Kedua pendapat di atas, memberi satu isyarat betapa pentingnya pembelajaran PKLH, dan sekaligus merupakan komitmen dan politikal will Pemerintah untuk melaksanakan PKLH pada semua jenis dan jenjang pendidikan di Indonesia. Walaupun rezim telah perganti, dan Menteri Pendidikan juga berganti namun substansi pembelajaran PKLH yang terintegrasi dengan pelajaran lain, hingga saat ini masih berlangsung dan diajarkan di setiap tingkat satuan pendidikan.

Pelaksanaan PKLH di Indonesia, secara resmi dilaksanakan pada semua jenjang sekolah sejak tahun 1976. (Hammado, 2011) dan diajarkan secara terintegrasi pada hampir seluruh mata pelajaran, khususnya pada tingkat SLTP Tetapi sejauh mana keberhasilan program tersebut, hingga pada saat ini belum ada jawaban yang tepat.

Seirama dengan apa yang menjadi wacana Pemerintah di atas, pada kesempatan ini Peneliti melakukan penelitian pada salah satu satuan pendidikan tingkat SMP untuk melihat dan mengevaluasi sejauh mana keberhasilan program tersebut. Khususnya untuk mengevaluasi tiga rana utama dalam PKLH, yaitu kognitif domain, afektif domain, dan psikomotorik domain yang diajarkan secara terintegrasi dengan hampir semua mata pelajaran di SMP, terutama pada pelajaran Ilmu Pengetahuan Alam, Ilmu Pengetahuan Sosial, dan Agama. Bahkan ada sekolah yang megajarkan secara monolitik melalui mata pelajaran Muatan lokal. Pada kesempatan ini Peneliti memilih SMP Negeri 1 Balla Kecamatan Balla Kabupaten Mamasa sebagai tempat penelitian. Peneliti ingin mengetahui ketiga domain PKLH pada sekolah tersebut, sebagai hasil pembelajaran PKLH secara terintegrasi dengan mata pelajaran lain.

Pendekatan pembelajaran secara terintegratif, (Deprikbud, 1989:34) adalah pendekatan yang didasarkan pada suatu pemikiran bahwa suatu mata pelajaran dapat diintegrasikan ke dalam mata pelajaran lain yang sesuai, yang dapat ditempuh dengan cara: 1) membangun unit atau seri bahan pelajaran yang disiapkan untuk diintegrasikan dengan mata pelajaran tertentu, 2) dengan core programming, yaitu bertitik tolak dari sebuah program inti dalam suatu mata pelajaran tertentu. Keuntungan dari sistem ini, adalah tidak perlu menambah tenaga guru, dan makin banyak tenaga guru yang terlibat. Namun juga tidak terlepas dari kelemahan, seperti perlunya tenaga guru dipersiapkan lebih dahulu, perlu mengubah silabus dan alokasi jam pembelajaran, kemungkinan tenggelamnya materi yang diintegrasikan dengan mata pelajaran inti, kesulitan mengevaluasi karena adanya dua tujuan yang harus dicapai dalam satu program pembelajaran, dan kesulitan-kesulitan lain yang mungkin timbul seperti kesulitan teknis edukatif dalam mengintegrasikan materi PKLH ke dalam mata pelajaran lainnya.

Mata pelajaran Ilmu Pengetahuan Alam dan mata pelajaran lainnya di SMP, diajarkan mulai dari kelas VII sampai kelas IX dengan alokasi waktu yang bervariasi/minggu. Materi pembelajaran tersebut, diharapkan dapat mencapai kompetensi untuk setiap bidang studi, misalnya mata pelajaran agama, mata pelajaran Ilmu Pengetahuan Sosial, mata pelajaran Ilmu Pengetahuan Alam dan mata pelajaran lainnya diajarkan secara terintegrasi dengan muatan PKLH.

Setelah mengamati Model Silabus dan Rencana Pelaksanaan Pembelajaran berdasarkan kurikulum di SMP, dijumpai bahwa materi pembelajaran PKLH yang diintegrasikan itu, ternyata diajarkan secara terintegratif dengan mata pelajaran Ilmu Pengetahuan Alam, Pendidikan Agama, Pendidikan Kewargaan Negara, Bahasa Indonesia, Ilmu Pengetahuan Sosial, Bahasa Inggris, Matematika, Seni dan Budaya, Penjaskes, Teknologi Informatika Komputer, dan Muatan lokal. Dengan demikian, hampir seluruh mata pelajaran di SMP boleh mengajarkan pokok bahasan PKLH secara terintegratif.

Dari sejumlah mata pelajaran yang diajarkan itu, ternyata muatan PKLH yang paling banyak, terintegrasi dengan mata pelajaran Ilmu Pengetahuan Alam dan dari segi konteks, mata pelajaran Ilmu Pengetahuan Alam di SMP, diajarkan mulai dari kelas VII sampai kelas IX dengan alokasi waktu 4 jam pelajaran/minggu. Kemudian pokok bahasan yang bermuatan PKLH ada lima, yaitu : 1) Gejala alam biotik dan abiotik, 2) Ekosistem, 3) Keanekaragaman makhluk hidup dalam pelestarian ekosistem, 4) Kepadatan populasi manusia hubungannnya dengan lingkungan, dan 5) Pencemaran dan kerusakan 
lingkungannya dengan aktivitas manusia. Kelima pokok bahasan tersebut diajarkan sebanyak 31 kali pertemuan, atau $31 \times 40$ menit $=1.240$ menit.

Selain mata pelajaran Ilmu Pengetahuan Alam, mata pelajaran Ilmu Pengetahuan Sosial juga lebih banyak membahas tentang lingkungan sosial. Kemudian materi pelajaran agama, lebih banyak membahas tentang makhluk dan alam ciptaan Tuhan yang perlu dihargai dan dipelihara..

\section{Penilaian Ranah Kognitif, Afektif, dan Psikomotorik}

Evaluasi merupakan tindakan untuk mengetahui sejauh mana tujuan yang telah ditetapkan. Dalam kaitannya dengan proses pembelajaran, evaluasi berfungsi sebagai alat untuk mengetahui keberhasilan proses dan hasil belajar siswa. Dalam sistem pendidikan nasional rumusan tujuan pendidikan, untuk mencapai kompetensi dasar maupun kompetensi bidang studi, menggunakan klasifikasi hasil belajar dari Benyamin Bloom yang secara garis besar membaginya menjadi tiga domain, yakni kognitif domain, afektif domain, dan psikomotorik domain.

Ketiga domain kejiwaan itu mempunyai hubungan yang sangat erat dan tidak dapat dilepaskan dari kegiatan atau proses evaluasi hasil belajar. Seperti yang dikatakan Benjamin S. Bloom (1956) bahwa pengelompokan tujuan pendidikan itu harus senantiasa mengacu kepada tiga jenis domain yang melekat pada diri peserta didik, yaitu: 1) Proses berpikir (cognitive domain), 2) Nilai atau sikap (affective domain) dan 3) Keterampilan (psychomotor domain). Dalam konteks evaluasi hasil belajar, ketiga domain tersebut harus dijadikan sasaran dalam kegiatan evaluasi hasil belajar. Sasaran kegiatan evaluasi hasil belajar adalah: 1) Apakah peserta didik sudah dapat memahami semua bahan ajar atau materi pelajaran yang telah diberikan kepada mereka? 2) Apakah peserta didik sudah dapat menghayati materi pelajaran tersebut? dan 3) Apakah materi pelajaran yang telah diberikan itu sudah dapat diamalkan secara kongkret dalam praktek atau dalam kehidupannya sehari-hari? Ketiga domain tersebut menjadi obyek penilaian hasil belajar. Diantara ketiga domain itu, domain kognitiflah yang paling banyak dinilai oleh para guru di sekolah karena berkaitan dengan kemampuan para siswa dalam menguasai isi bahan pelajaran.

\section{METODE PENELITIAN}

Penelitian ini bertujuan untuk mengetahui keberhasilan program pembelajaran PKLH khususnya untuk mengevaluasi tiga aspek utama dalam PKLH, yaitu kognitif, afektif, dan psikomotorik yang diajarkan secara terintegrasi dengan mata pelajaran lain di SMP, Negeri 1 Balla. Populasi penelitian ini adalah seluruh siswa SMP Negeri 1 Balla, yang terdiri atas Kelas VII $=97$ orang, Kelas $\mathrm{VIII}=88$ orang, sehingga jumlah populasi $=185$ orang. Sampel dalam penelitian ini ditetapkan sebesar 134 orang siswa, diambil secara probability proportionate stratified random sampling. Variabel penelitian, yaitu: 1) Proses berpikir (cognitive domain), 2) Sikap (affective domain) dan 3) Keterampilan (psychomotor domain) tentang materi PKLH. Data dalam penelitian ini adalah hasil tes terhadap responden, yaitu tes yang dilakukan untuk mengetahui pengetahuan, sikap, dan keterampilan para siswa SMP Negeri 1 Balla tentang hal-hal yang berhubungan dengan materi PKLH. Data dianalisis secara deskriftif dan regresi ganda dengan menggunakan software SPSS sebagai alat bantu.

\section{HASIL DAN PEMBAHASAN \\ Hasil Penelitian}

Kognitif, afektif, dan psykomotorik adalah kemampuan intelektual atau kecerdasan yang dicapai oleh siswa yang terbentuk dari pemikiran, pengetahuan, pemahaman, dan pemecahan masalah setelah belajar tentang materi PKLH yang diajarkan secara terintegrasi dengan mata pelajaran lain. Untuk mengukur kemampuan tersebut, data yang telah diperoleh melalui hasil tes yang dikerjakan siswa dianalisis dengan statistik deskriptif dan hasil analisis tersebut dapat dilihat pada tabel 1 . 
Tabel 1. Deskriptif Kognitif, Afektif, dan Psykomotorik siswa SMP Negeri 1 Balla Tahun 2017

\begin{tabular}{lrrrrr}
\hline & N & Minimum & Maximum & \multicolumn{1}{l}{ Mean } & Std. Deviation \\
\hline Kognitif & 135 & 8,00 & 92,00 & 44,7111 & 15,98454 \\
\hline Afektif & 135 & 12,00 & 100,00 & 60,1407 & 16,18234 \\
\hline Psikomotorik & 135 & 12,00 & 100,00 & 60,5778 & 13,10376 \\
\hline Valid N (listwise) & 135 & & & & \\
\hline
\end{tabular}

Sumber : Hasil Analisis (Output SPSS) 2017.

Untuk menjawab rumusan masalah pertama, berdasarkan tabel 1. di atas diperoleh nilai minimum siswa pada variabel Kognitif sebesar 8 dan nilai maksimum sebesar 92. Untuk hasil analisis deskriptif nilai siswa diukur dengan 5 kategori, yaitu sangat rendah, rendah, sedang, tinggi, dan sangat tinggi. Hasil tersebut dapat dilihat pada tabel frekwensi (tabel 2) di bawah ini.

Tabel 2 Distibusi Frekwensi Siswa Berdasarkan Nilai Kognitif

\begin{tabular}{cccccc}
\hline No & $\begin{array}{c}\text { Skala } \\
\text { Angka }\end{array}$ & Kategori & $\begin{array}{c}\text { Frekwensi } \\
(\mathrm{F})\end{array}$ & $\begin{array}{c}\text { Persentase } \\
(\%)\end{array}$ & $\begin{array}{c}\text { Mean/ } \\
\text { Kategori }\end{array}$ \\
\hline 1. & $8-25$ & Sangat rendah & 21 & 15 & \\
2. & $26-48$ & Rendah & 54 & 40 & 44,71 \\
3. & $49-59$ & Sedang & 42 & 32 & (Rendah) \\
4. & $60-76$ & Tinggi & 15 & 11 & \\
5. & $77-92$ & Sangat tinggi & 3 & 2 & \\
\hline & Total & & 135 & 100 & \\
\hline
\end{tabular}

Sumber: Hasil Analisis

Dari tabel 2. di atas, dapat diketahui bahwa nilai kognitif siswa pada penelitian ini, jumlah siswa yang memperoleh nilai sangat rendah sebanyak 21 orang (15\%), yang memperoleh nilai rendah sebanyak 54 orang (40\%), memperoleh nilai sedang sebanyak 42 orang (32\%), yang memperoleh nilai tinggi sebanyak 15 orang (11\%), dan memperoleh nilai sangat tinggi sebanyak 3 orang (2\%). Kemudian nilai mean/kategori $=44,71$ sehingga kesimpulan hasil penelitian ini bahwa kognitif siswa tentang PKLH yang diajarkan secara terintegrasi di SMP Negeri 1 Balla berada pada kategori rendah. Hasil analisis ini memberi gambaran kurang efektifnya sistem pembelajaran PKLH yang diajarkan secara terintegratif.

Selanjutnya, untuk menjawab rumusan masalah kedua, berdasarkan tabel 1. di atas diperoleh nilai minimum siswa pada variabel afektif sebesar 12 dan nilai maksimum sebesar 100. Untuk hasil analisis deskriptif nilai siswa diukur dengan 5 kategori, yaitu sangat rendah, rendah, sedang, tinggi, dan sangat tinggui. Hasil tersebut dapat dilihat pada tabel frekwensi (tabel 3) di bawah ini.

Tabel 3 Distibusi Frekwensi Siswa Berdasarkan Nilai Apektif

\begin{tabular}{cccccc}
\hline No & $\begin{array}{c}\text { Skala } \\
\text { Angka }\end{array}$ & Kategori & $\begin{array}{c}\text { Frekwensi } \\
(\mathrm{F})\end{array}$ & $\begin{array}{c}\text { Persentase } \\
(\%)\end{array}$ & $\begin{array}{c}\text { Mean/ } \\
\text { Kategori }\end{array}$ \\
\hline 1. & $12-30$ & Sangat rendah & 6 & 5 & \\
2. & $31-47$ & Rendah & 10 & 7 & 60,14 \\
3. & $48-65$ & Sedang & 83 & 62 & (Sedang) \\
4. & $66-84$ & Tinggi & 26 & 19 & \\
5. & $85-100$ & Sangat Tinggi & 10 & 7 & \\
\hline & Total & & 135 & 100 & \\
\hline
\end{tabular}

Sumber: Hasil Analisis

Dari tabel 3. di atas, dapat diketahui bahwa nilai afektif siswa pada penelitian ini, jumlah siswa yang memperoleh nilai sangat rendah sebanyak 6 orang (5\%), yang memperoleh nilai rendah sebanyak 10 orang (7\%), memperoleh nilai sedang sebanyak 83 orang (62\%) memperoleh nilai tinggi sebanyak 26 orang (9\%), dan yang memperoleh nilai sangat tinggi sebanyak 10 orang (7\%). Kemudian nilai 
mean/kategori $=60,14$ sehingga kesimpulan hasil penelitian ini bahwa nilai afektif siswa tentang PKLH yang diajarkan secara terintegrasi pada SMP Negeri 1 Balla adalah sedang. Hasil analisis ini memberi gambaran tidak efektifnya sistem pembelajaran PKLH yang diajarkan secara terintegratif.

Untuk menjawab rumusan masalah ketiga, berdasarkan tabel 1. di atas diperoleh nilai minimum siswa pada variabel psykomotorik sebesar 12 dan nilai maksimum sebesar 100. Untuk hasil analisis deskriptif nilai siswa diukur dengan 5 kategori, yaitu sangat rendah, rendah, sedang, tinggi, dan sangat tinggi. Hasil tersebut dapat dilihat pada tabel frekwensi (tabel 4) di bawah ini.

Tabel 4 Distibusi Frekwensi Siswa Berdasarkan Psykomotorik

\begin{tabular}{cccccc}
\hline No & $\begin{array}{c}\text { Skala } \\
\text { Angka }\end{array}$ & Kategori & $\begin{array}{c}\text { Frekwensi } \\
(\mathrm{F})\end{array}$ & $\begin{array}{c}\text { Persentase } \\
(\%)\end{array}$ & $\begin{array}{c}\text { Mean/ } \\
\text { Kategori }\end{array}$ \\
\hline 1. & $12-30$ & Sangat rendah & 2 & 1,5 & \\
2. & $31-47$ & Rendah & 5 & 3,5 & 60,57 \\
3. & $48-65$ & Sedang & 97 & 72 & (Sedang) \\
4. & $66-84$ & Tinggi & 23 & 17 & \\
5. & $85-100$ & Sangat tinggi & 8 & 6 & \\
\hline & Total & & 135 & 100 & \\
\hline
\end{tabular}

Sumber: Hasil Analisis

Dari tabel 4. di atas, dapat diketahui bahwa nilai psykomotorik siswa pada penelitian ini, jumlah siswa yang memperoleh nilai sangat rendah sebanyak 2 orang $(1,5 \%)$, yang memperoleh nilai rendah sebanyak 5 orang $(3,5 \%)$, memperoleh nilai sedang sebanyak 97 orang $(72 \%)$, yang memperoleh nilai tinggi sebanyak 23 orang (17\%), dan yang memperoleh nilai sangat tinggi sebanyak 8 orang (6\%). Kemudian nilai mean/kategori $=60,57$ sehingga kesimpulan hasil penelitian ini menunjukkan bahwa psykomotorik siswa tentang pembelajaran PKLH secara terintegrasi dengan mata pelajaran lain di SMP Negeri 1 Balla adalah sedang. Hasil analisis ini tergambar bahwa pengetahuan rendah, pemahaman sedang, dan tindakan atau psikomotoriknya juga sedang.

Teknik analisis regresi linear ganda dimaksudkan untuk melihat hubungan antar variabel, untamanya variabel kognitif dan variabel apektif sebagai variabel independen, dengan variabel psykomotorik sebagai variabel dependen. Dalam analisis ini, peneliti mempergunakan bantuan software SPSS dan output SPSS sebagai hasil analisis dapat dilihat pada tabel 5.

Tabel 5 Output SPSS Untuk Mengetahui Hasil Signifikansi pada Uji Rgresi Linier Ganda

$\operatorname{ANOVA}(\mathbf{b})$

\begin{tabular}{|c|c|c|c|c|c|c|}
\hline Model & & $\begin{array}{l}\text { Sum of } \\
\text { Squares }\end{array}$ & df & Mean Square & $\mathrm{F}$ & Sig. \\
\hline \multirow[t]{3}{*}{1} & Regression & 15745,246 & 2 & 7872,623 & 143,066 &, $000(a)$ \\
\hline & Residual & 7263,687 & 132 & 55,028 & & \\
\hline & Total & 23008,933 & 134 & & & \\
\hline
\end{tabular}

a Predictors: (Constant), Afektif, Kognitif

Berdasarkan tabel 5. di atas, hasil analisis dalam penelitian ini terbukti sangat signifikan karena nilai Sig lebih kecil dari 0,01 $(0,000<0,01)$. Artinya, Kognitif, dan Afektif PKLH Siswa SMP Negeri 1 Balla berpengaruh dan sangat signifikan terhadap Psykomotorik Siswa.

Untuk mengetahui berapa besar kontribusi variabel independen Kognitif, dan Afektif terhadap variabel dependen Psykomotorik, output SPSS sebagai hasil analisis dapat dilihat pada tabel 6. 
Tabel 6 Output SPSS Untuk Mengetahui Besar R Square

dan Otokorelasi (Durbin Watson)

\section{Model Summary(b)}

\begin{tabular}{lccccr}
\hline Model & $\mathrm{R}$ & $\mathrm{R}$ Square & $\begin{array}{c}\text { Adjusted R } \\
\text { Square }\end{array}$ & $\begin{array}{c}\text { Std. Error of the } \\
\text { Estimate }\end{array}$ & Durbin-Watson \\
\hline 1 &, $827(\mathrm{a})$ &, 684 &, 680 & 7,41808 & 2,146 \\
\hline a Predictors: (Constant), Afektif, Kognitif & & & \\
b Dependent Variable: Psikomotorik & & & \\
Sumber: Hasil Analisis & &
\end{tabular}

Dari output SPSS bedasarkan tabel 6. di atas, didapatkan nilai R Square $\left(\mathrm{R}^{2}\right)$ menunjukkan sumbangan atau konstribusi kognitif, dan afektif sebesar 68,4 \% (0,684 x 100) sedangkan sisanya 31,6 $\%$ ( $100 \%-68,4 \%)$ dipengaruhi oleh variabel lain.

Selanjutnya untuk melihat variabel mana yang berpengaruh paling kuat terhadap variabel Psykomotorik output SPSS sebagai hasil analisis dapat dilihat pada tabel 7.

Tabel 7 Output SPSS Untuk Nilai Beta dan Mengetahui Multikolinieritas

\section{Coefficients(a)}

\begin{tabular}{|c|c|c|c|c|c|c|}
\hline \multirow[b]{2}{*}{ Model } & & \multicolumn{2}{|c|}{$\begin{array}{l}\text { Unstandardized } \\
\text { Coefficients }\end{array}$} & $\begin{array}{l}\text { Standardized } \\
\text { Coefficients }\end{array}$ & \multirow{2}{*}{$\mathrm{t}$} & \multirow{2}{*}{$\begin{array}{c}\text { Sig. } \\
\text { Std. Error }\end{array}$} \\
\hline & & B & Std. Error & Beta & & \\
\hline \multirow[t]{3}{*}{$\overline{1}$} & (Constant) & 20,127 & 2,625 & & 7,667 & ,000 \\
\hline & Kognitif & ,008 &, 044 & ,010 & , 186 & ,853 \\
\hline & Afektif & ,667 & ,043 & ,823 & 15,374 & ,000 \\
\hline
\end{tabular}

Berdasarkan hasil analisis pada tabel 7. di atas, dapat dilihat pada kolom standardized Ceofficients Beta, diantara 2 variabel ternyata variabel afektif memiliki nilai Beta yang lebih besar $(0,823)$. Artinya, variabel afektif memiliki pengaruh yang lebih kuat terhadap psykomotorik. Atau dengan kata lain, sikap (affective domain) yang mencakup watak perilaku seperti persaan, minat, sikap, dan emosi para siswa SMP Negeri 1 Balla terhadap nilai-nilai PKLH dalam kehidupan sehari-hari memiliki pengaruh yang lebih besar terhadap keterampilan (psychomotor domain) atau kemampuan bertindak setelah siswa menerima pengalaman belajar materi PKLH, atau bagaimana kemampuan para siswa SMP Negeri 1 Balla untuk mengimplementasikan materi PKLH dalam praktek kehidupan seharihari, baik di lingkungan sekolah maupun di lingkungan keluarga dan masyarakat.

Oleh sebab itu, dapat disimpulkan bahwa melalui hasil analisis uji regresi linear ganda, kognitif, dan afektif PKLH siswa SMP Negeri 1 Balla terbukti sangat signifikan mempengaruhi psykomotorik siswa dengan kontribusi sebesar $68,4 \%$. 


\section{PEMBAHASAN}

Tujuan penelitian ini adalah ingin mengetahui kognitif domanin, afektif domanin, dan psykomotorik domanin siswa SMP Negeri 1 Balla tentang materi pembelajaran PKLH yang diajarkan secara terintegasi dengan mata pelajaran lain, seperti yang dituangkan di dalam model Pendidikan Kependudukan dan Lingkungan Hidup dengan Pendekatan pembelajaran secara terintegratif, (Deprikbud, 1989 : 34), serta Model Silabus dan Rencana Pelaksanaan Pembelajaran Mata Pelajaran : Ilmu Pengetahuan Alam SMP/MTS ( Depdiknas 2006),

Secara teoritis dikatakan bahwa kognitif terbentuk berdasarkan pemikiran, pengetahuan, pemahaman, dan cara pemecahan masalah yang dimiliki, dalam hal ini tentang materi PKLH yang diajarkan secara terintegratif. Oleh sebab itu, dalam penelitian ini selain mengukur tingkat kognitif siswa, juga mengukur tingkat afektif dan psykomotorik siswa tentang PKLH dengan tujuan untuk memberi bahan pemikiran dalam perbaikan kurikulum dan atau pembelajaran PKLH di sekolah.

Hasil penelitian membuktikan bahwa kognitif domain siswa SMP Negeri 1 Balla tentang materi PKLH yang diajarkan secara terintegratif ternyata rendah. Hal ini membuktikan bahwa sistem pembelajaran yang dilakukan belum efektif. Demikian juga dengan domain yang lain, yaitu afektif domain dan psykomotorik domain siswa hanya berada pada kategori sedang. Hasil analisis ini, menunjukkan bahwa proses pembelajaran PKLH yang diajarkan secara terintegrasi dengan mata pelajaran lain, terbukti bahwa belum menunjukkan hasil yang memuaskan. Ada kemungkinan, siswa tidak menyadari bahwa sesungguhnya materi yang disajikan dalam mata pelajaran yang mereka ikuti, adalah materi PKLH yang diajarkan guru secara terintegrasi. Oleh sebab itu, ada baiknya jika guru yang mengajar menjelaskan kepada siswanya bagaimana keterkaitan materi pelajaran yang disampaikan berkaitan dengan PKLH, terutama menjelaskan bagaimana pentingnya memelihara lingkungan hidup sebagai habitat makhluk hidup, dan makhluk hidup tidak akan dapat hidup tanpa adanya lingkungan yang baik. Satu hal yang juga perlu dipertimbangkan adalah bagaimana agar para pemangku kebijakan di Dinas Pendidikan menyadari betapa pentingnya melestarikan lingkungan hidup. Oleh sebab itu, jika para pemangku kebijakan menyadari hal itu, ada baiknya mengambil kebijakan untuk memperbaiki kurikulum misalnya mata pelajaran PKLH tidak lagi diajarkan secara terintegrasi tetapi dapat diajarkan secara monolitik sebagai muatan lokal agar materinya dapat lebih dipahami para siswa, dan pada gilirannya akan tertanam di dalam jiwanya serta membentuk kognitif, afektif, dan psykomotorik siswa yang lebih baik tentang PKLH, serta memahami betapa pentingnya peranan mereka untuk melestarikan alam demi kehidupan manusia masa kini, dan kehidupan generasi yang akan datang.

Melalui penelitian ini, sekaligus menguji teori yang mengatakan bahwa ranah kognitif, dan afektif, sangat berperan untuk membentuk psykomotorik peserta didik untuk melakukan atau tidak melakukan sesuatu. Berdasarkan hasil analisis regresi linear ganda untuk mengetahui apakah kedua variabel tersebut berpengaruh terhadap psykomotorik, terbukti bahwa variabel kognitif, dan afektif berpengaruh secara positif dan signifikan terhadap psykomotorik. Bahkan didapatkan nilai $\mathrm{R}$ Square $\left(\mathrm{R}^{2}\right)$ menunjukkan bahwa sumbangan atau konstribusi variabel kognitif, dan afektif sebesar $68,4 \%$ Artinya bahwa semakin baik nilai kognitif dan afektif siswa tetang materi PKLH, semakin baik pula keterampilan atau kemampuan bertindak atau kemampuan para siswa SMP Negeri 1 Balla untuk mengimplementasikan materi PKLH dalam praktek kehidupan sehari-hari, baik di lingkungan sekolah maupun di lingkungan keluarga dan masyarakat.

\section{KESIMPULAN}

Berdasarkan hasil analisis data dan pembahasan yang dilakukan dalam penelitian ini, dapat disimpulkan bahwa : 1) Kognitif domain siswa SMP Negeri 1 Balla tentang pembelajaran PKLH secara terintegrasi dengan pelajaran lain, berada pada kategori rendah 2) Afektif domain siswa SMP Negeri 1 Balla tentang pembelajaran PKLH secara terintegrasi dengan pelajaran lain, berada pada kategori sedang, 3) Psikomotorik domain siswa SMP Negeri 1 Balla tentang pembelajaran PKLH secara terintegrasi dengan pelajaran lain, berada pada kategori sedang. Kemudian hasil analisis regersi memperlihatkan bahwa terdapat hubungan yang signifikan antara variabel kognitif dan afektif terhadap 
variabel psikomotorik dengan nilai kontribusi sebesar $68,4 \%$. Ini berarti masih ada variabel lain sebesar $31,6 \%$ yang berpengaruh terhadap Psikomotorik domain siswa, namun tidak dibahas dalam penelitian ini.

\section{SARAN}

Berdasarkan kesimpulan di atas, yang merujuk kepada hasil penelitian sehingga disarankan halhal sebagai berikut: 1) Disarankan kepada para pemangku kebijakan di bidang Pendidikan secara unum agar materi PKLH dapat diajarkan secara monolitik bagi seluruh siswa, dengan menempatkan mata pelajaran PKLH sebagai mata pelajaran muatan lokal. 2) Juga disarankan kepada para guru yang mengajarkan materi PKLH secara terintegrasi agar memberi penjelasan keterkaitan materi pelajaran yang diajarkan dengan materi PKLH secara terintegrasi. Agar siswa memahami betapa besarnya peranan mereka untuk melestarikan lingkungan dimana manusia hidup, dan juga memperhitungkan kehidupan generasi yang akan datang.

\section{Referensi}

Hammado, 2011. Hand Out Perkuliahan Filsafat PKLH. PPS-UNM 